\title{
\#lasperiodistasparamos, gestación de una conciencia profesional feminista
}

\author{
\#lasperiodistasparamos, gestation of a feminist \\ professional conscience
}

\author{
María Iranzo-Cabrera
}

Cómo citar este artículo:

Iranzo-Cabrera, María (2020). "\#lasperiodistasparamos, gestación de una conciencia profesional feminista”. El profesional de la información, v. 29, n. 2, e290222.

https://doi.org/10.3145/epi.2020.mar.22

Artículo recibido el 12-06-2019 Aceptación definitiva: 17-12-2019

Primera publicación: 30-03-2020 Publicación versión corregida: 07-06-2021

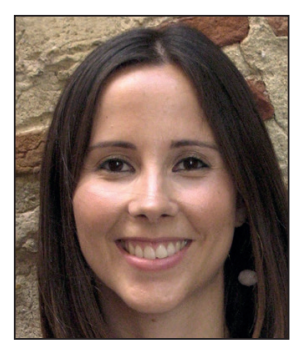

María Iranzo-Cabrera

https://orcid.org/0000-0002-6237-6041

Universitat de València

Facultad de Filología, Traducción y Comunicación

Dto. de Teoría de los Lenguajes y CC. de la Comunicación

Avenida Blasco Ibáñez, 32. 46010 Valencia, España

maria.iranzo-cabrera@uv.es

\section{Corrigendum}

Iranzo-Cabrera, María (2020). "\#lasperiodistasparamos, gestación de una conciencia profesional feminista”. El profesional de la información, v. 29, n. 2, e290222.

https://doi.org/10.3145/epi.2020.mar.22

Este artículo se publicó en su momento con diversas omisiones de citas y referencias por parte de su autora, que se detallan a continuación.

Las frases que se tomaron de artículos de otros autores sin citarse debidamente se señalan en color azul:

1)

Artículo publicado originalmente en EPI (p. 4, líneas 2-26)

No obstante, contamos con aportes teóricos sobre la participación de las mujeres en los escenarios de producción periodística desde 1970. En esta década se institucionalizó en la mayoría de las disciplinas sociales y humanas la perspectiva de género como deriva del pensamiento feminista (Lagarde, 1996). Desde entonces investigadoras de distintas áreas temáticas del campo de la sociología y de la comunicación han ofrecido categorías de análisis y enfoques metodológicos novedosos.

La sociología de la comunicación y la teoría de la comunicación de masas con enfoque de género han investigado la relación de los medios con la cultura, la significación de los mensajes en la construcción de la diferencia sexual, la identidad femenina y el sesgo de los estereotipos de género en la reproducción de la ideología dominante (Gallagher, 1979; Mattelart, 1982; Fagoaga; Secanella, 1984, entre otras).

Por su parte la sociología de género se ha centrado en el análisis del empleo femenino, la incorporación de la mujer en el mercado de trabajo y las transformaciones intrafamiliares (Borderías-Mondéjar; Carrasco-Bengoa; Alemany, 1994; Dema-Moreno; Díaz-Martínez, 2010). Cabe citar aquí la perspectiva teórica del newsmaking, interesada en las estructuras, las rutinas y la cultura profesional periodística (Wolf, 1987; Gallego, 1994; 2002); y los aportes provenientes de la sociología de la profesión periodística que observa aspectos como la identidad profesional (Ortega; Humanes, 2000), las condiciones y los roles en el trabajo (García-de-Cortázar; García-de-León, 2000).

Fue en la Conferencia de Beijing (1995) cuando se otorgó mayor visibilidad internacional al tema de las desigualdades entre mujeres y varones en todos los ámbitos de la vida como un problema de derechos. En este marco se identificó como 
elemento fundamental y originador de estas causas el limitado acceso de las mujeres a los medios de comunicación y a las tecnologías de información, en términos de representación y de empleo. A partir de allí, algunos áreas de gestión política internacional propagaron la idea de que las imágenes estereotipadas de las mujeres en las industrias mediáticas y su escasa participación como propietarias y productoras en los medios de comunicación son poderosas barreras que dificultan la universalidad de los derechos humanos (Chocarro, 2007; Chaher; Santoro, 2007)

Fuente original, no citada ni referenciada: Rovetto Gonem, 2013 (p. 56, párrafos 4 y 5, p. 57, párrafos 1 y 3) No obstante, podríamos situar el inicio de los mismos en la década del 70, período en el cual se institucionaliza, en la mayoría de las disciplinas sociales y humanas, la perspectiva de género como deriva del pensamiento feminista (Lagarde, 1996).

Pero a su vez, en el campo específico de los estudios sobre la participación de las mujereszen los escenarios de producción periodística contamos con aportes teóricos que, a partir de la década del ' 80 , convergen desde distintas áreas temáticas del campo de la sociología y de la comunicación, ofreciendo categorías de análisis y enfoques metodológicos novedosos: la sociología de la comunicación y la teoría de la comunicación de masas con enfoque de género, preocupadas por la relación de los media con la cultura, la significación de los mensajes en la construcción de la diferencia sexual, la identidad femenina y el sesgo de los estereotipos de género en la reproducción de la ideología dominante (Gallagher, 1979; 1981; Mattelart; Jordà, 1982; Fagoaga; Secanella, 1984, entre otras); la sociología de género, centrada en el análisis del empleo femenino, la incorporación de la mujer en el mercado de trabajo, las transformaciones intrafamiliares (Borderías et al., 1994); la perspectiva teórica del Newsmaking, interesada en las estructuras, las rutinas y la cultura profesional periodística (Wolf, 1979; 1987); y los aportes provenientes de la sociología de la profesión periodística que observa aspectos como la identidad profesional (Ortega; Humanes, 2000), las condiciones y roles en el trabajo (García-de-Cortázar; García-de-León, 2000) y la incompatibilidad entre vida profesional y privada (Papi-Gálvez, 2008).

Ciertamente, con la Conferencia de Beijing se otorgó mayor visibilidad internacional al tema de las desigualdades entre mujeres y varones en todos los ámbitos de la vida como un problema de derechos; se identificó como elemento fundamental y originador de estas causas, al limitado acceso de las mujeres a los medios de comunicación y a las tecnologías de información, en términos de representación y de empleo. A partir de allí, algunos ámbitos de gestión política internacional propagaron la idea de que las imágenes estereotipadas de las mujeres en las industrias mediáticas, y su escasa participación como propietarias y productoras en los medios de comunicación son poderosas barreras que dificultan la universalidad de los derechos humanos (Chocarro, 2007; Chaher; Santoro, 2007).

\section{2)}

\section{Artículo publicado originalmente en EPI (p. 3, líneas 17-18)}

Es así como en la segunda década del siglo XXI se ha configurado lo que ya se considera una nueva ola feminista (Knappe; Lang, 2014; Cobo, 2019); esto es, una conciencia social crítica frente a la desigualdad y la explotación económica y sexual de las mujeres.

\section{Fuente original, referenciada pero no citada ni entrecomillada: Cobo, 2019 (p. 134, párrafo 2)}

La globalización del feminismo pone de manifiesto tanto la fortaleza de las ideas feministas como el crecimiento de la conciencia social crítica frente a la desigualdad y la explotación económica y sexual de las mujeres

\section{3)}

\section{Artículo publicado originalmente en EPI (p. 3, líneas 18-19)}

Su cuerpo vindicativo es la violencia sexual, un mecanismo global de control social que impide a las mujeres tanto apropiarse del espacio público como hacer uso de su autonomía y libertad.

\section{Fuente original, referenciada pero no citada ni entrecomillada: Cobo, 2019 (p. 138, párrafo 2)}

La violencia sexual es un poderoso mecanismo de control social que impide a las mujeres tanto apropiarse del espacio público como hacer uso de su autonomía y libertad

\section{4)}

\section{Artículo publicado originalmente en EPI (p. 3, líneas 20-23)}

La magnitud de algunas de estas movilizaciones y el hecho de que se hayan producido en distintos continentes casi al mismo tiempo han convertido al feminismo en un movimiento de masas por cuarta vez en su historia

\section{Fuente original, referenciada pero no citada ni entrecomillada: Cobo, 2019 (p. 134, párrafo 1)}

La magnitud de algunas de estas movilizaciones y el hecho de que se hayan producido en distintos continentes casi al mismo tiempo han convertido al feminismo en un movimiento de masas por tercera vez en su historia 


\section{5)}

Artículo publicado originalmente en EPI (p. 3, líneas 27-29)

y a la corriente de feminismos en plural que en la década de los 90 del siglo pasado planteaba posibilidades de deconstrucción de los patrones identitarios y alineados con un sólo tipo de feminismo. Fruto de aquella reorganización de los discursos se multiplicaron los posicionamientos, los matices y las diferencias (McRobbie, 2009)

Fuente original, referenciada pero no citada ni entrecomillada: Reverter-Bañón, 2013 (p. 458, párrafo 2)

"feminismos" en plural, para atender de manera más coherente a las posibilidades de deconstrucción de los patrones identitarios de alienación. Fruto de esta reorganización de los discursos feministas se multiplican los posicionamientos, los matices y las diferencias feministas

6)

\section{Artículo publicado originalmente en EPI (p. 3, líneas 34-35)}

Plant defiende que la realidad virtual del ciberespacio puede acabar con la visión del mundo y la realidad material construida durante dos mil años por el orden patriarcal.

Fuente original, no citada ni referenciada: Reverter Bañón, 2001 (p. 39, párrafo 3)

Plant cree, desde mi opinión a veces demasiado utópicamente, que la realidad virtual del ciberespacio puede acabar con la visión del mundo y la realidad material construida durante dos mil años por el orden patriarcal

\section{7)}

\section{Artículo publicado originalmente en EPI (p. 3, líneas 36-37)}

la cibercultura no sólo no ha cambiado los estereotipos de género, sino que incluso está sirviendo para acentuar más la dominación y opresión de las mujeres

\section{Fuente original, no citada ni referenciada: Reverter Bañón, 2001 (p. 41, párrafo 3)}

Según esta reflexión la cibercultura no sólo no ha cambiado los estereotipos de género, sino que incluso está sirviendo para acentuar más la dominación y opresión de las mujeres.

\section{8)}

\section{Artículo publicado originalmente en EPI (p. 3, líneas 40-41)}

Para De-Miguel y Boix (2002) lo que diferencia a la actual ola feminista es que ahora se trata de un "ciberfeminismo social", esto es, un ciberfeminismo con una agenda de lucha política y de transformación social.

Fuente original, referenciada pero no citada ni entrecomillada: Reverter-Bañón, 2013 (p. 456, párrafo 3) como ha hecho Monserrat Boix (2002) al Ilamar "ciberfeminismo social" a un ciberfeminismo con una agenda de lucha política y de transformación social.

\section{9)}

\section{Artículo publicado originalmente en EPI (p. 3, penúltimo párrafo)}

El proceso se ha realizado al revés que en las anteriores olas feministas: se han conectado ideológicamente con las vindicaciones feministas, y ahora es cuando se están acercando a grupos feministas, ya organizados en unos casos y en otros recién constituidos.

Fuente original (p. 135, segundo párrafo)

https://riuma.uma.es/xm/ui/bitstream/handle/10630/17716/134\%20Cobo.pdf

Al tener conocimiento de las malas prácticas que se acaban de exponer, la revista Profesional de la información reunió una Comisión de investigación para analizar este caso. Tras deliberar, la Comisión ha decidido lo siguiente:

"Si bien las omisiones de citas y comillas son interpretables como plagio, se observa que se localizan solo en la parte introductoria del artículo, y que la parte de recogida de datos y análisis de resultados es original y aporta resultados válidos para el avance de la Ciencia. Es decir, el estudio conserva una parte inédita y de interés científico.

Por lo anterior, esta Comisión ha decidido no retractar el artículo, sino volverlo a publicar incluyendo las acreditaciones de autorías omitidas en la versión de la autora de marzo de 2020, y añadir este corrigendum para que los lectores pasados y futuros estén debidamente informados de lo sucedido". 


\section{Resumen}

Se analiza la gestación y consolidación del activismo feminista que ha aglutinado a miles de profesionales de la comunicación en España a raíz de la huelga del 8 de marzo de 2018, unidas a través de la aplicación de mensajería Telegram y por el hashtag \#lasperiodistasparamos en la red de microblogging Twitter. Se ha llevado a cabo un análisis del discurso de los 13.163 tweets publicados de febrero a septiembre de 2018 con esa etiqueta. También se ha analizado el contenido de las conversaciones en su canal de Telegram. Se aportan las opiniones formuladas en entrevistas en profundidad a 20 activistas de esta cibercomunidad. A través de una metodología cuantitativa y cualitativa aplicada a categorías extraídas en los discursos, se han observado las causas de este activismo, la eficacia de sus canales de organización y comunicación y las iniciativas derivadas en el espacio urbano. En conclusión, esta pionera concienciación de unidad gremial ha estado motivada por la crisis del capitalismo y por una nueva ola feminista global, tecnológica e intergeneracional. Este activismo de las comunicadoras españolas ha conseguido por primera vez abordar el feminismo desde los grandes medios de masas y ha sumado a la protesta a mujeres de diversas edades, ideologías y profesiones. Además, ha derivado en la constitución de diversas organizaciones y asociaciones de profesionales del periodismo, redes más pequeñas con capacidad de decidir y actuar por el feminismo dentro del espacio urbano en el ámbito autonómico. Especialmente trabajan por la concienciación deontológica por la perspectiva de género en la producción periodística.

\section{Palabras clave}

Feminismo; Género; Periodismo; Periodistas; Profesionales; Derechos laborales; Igualdad de género; Ciberactivismo; Estudios sobre género; Teoría política feminista; Perspectiva de género; Medios sociales; Redes sociales; Acción política; Colectividad profesional; Hashtivismo; Twitter; Telegram; Hashtags; \#lasperiodistasparamos.

\section{Abstract}

The gestation and consolidation of feminist activism that has brought together thousands of communication professionals in Spain, following the strike called on March 8, 2018 are analyzed. United through the Telegram messaging application and through the hashtag \#lasperiodistasparamos on Twitter, a speech analysis of the 13,163 tweets published with this label, from February to September 2018, has been carried out. The content of the conversations on their Telegram channel has also been analyzed as well as the opinions formulated in in-depth interviews with 20 activists of this cyber community. Through a quantitative and qualitative methodology applied to categories extracted in the speeches, the causes of this activism, the effectiveness of its channels of organization and communication and the initiatives derived in the urban space have been observed. In conclusion, this pioneering awareness of union between Spanish communication professionals has been motivated by the crisis of capitalism and by a new global, technological and intergenerational feminist wave. This activism has managed for the first time to cover feminism from the mass media and has added to the protest women of different ages, ideologies and professions. In addition, it has resulted in the constitution of various organizations and associations of journalism professionals, smaller networks with the ability to decide and act for feminism within the urban space in regional areas. Especially they work for deontological awareness for the gender perspective in journalistic production.

\section{Keywords}

Feminism; Gender; Journalism; Journalists; Professionals; Labour rights; Gender equality; Cyberactivism; Gender studies; Feminist political theory; Gender perspective; Social networks; Social media; Political action; Professional community; Hashtivism; Twitter; Telegram; Hashtags; \#lasperiodistasparamos.

Financiación

Este artículo es un resultado de la investigación que lleva a cabo el grupo de I+D Mediaflows (CSO2016-77331-C2-1-R).

Agradecimiento

Agradezco la orientación y asesoramiento del investigador y analista de inteligencia artificial de la Universitat de València Jordi Silvestre en la recogida de los datos contenidos en los tweets con el hashtag \#lasperiodistasparamos.

\section{Introducción}

\subsection{Una nueva ola feminista}

El surgimiento de nuevos movimientos urbanos de oposición al sistema capitalista no puede desvincularse de un contexto de crisis política, económica y cultural que brotó a principios del siglo XXI (Castells, 2015). A raíz de la crisis financiera de 2008, el neoliberalismo provocó entre otros efectos una inestabilidad y vulnerabilidad laboral que afectó especialmente a mujeres y grupos minoritarios. Paradójicamente, el capitalismo global que desde los años 90 del siglo pasado había cuestionado el feminismo poniendo énfasis en valores individualistas como el empoderamiento, la libertad, la flexibilidad, la movilidad y el acceso a la sociedad de consumo, provocó tal situación de soledad e inseguridad que hizo resurgir la necesidad de una política crítica feminista (Baer, 2016). 
Sobre el periodismo se ha ceñido no sólo la crisis económica, sino también otra estructural derivada de la digitalización de la sociedad. Entre 2008 y 2015 se destruyeron más de 12.200 empleos en los medios, según la Federación de Asociaciones de Periodistas de España. Además de recortes de plantilla y expedientes de regulación de empleo en medios (Telemadrid, RTVE, El país...), la figura de colaborador y los contratos temporales hicieron evidente la precariedad laboral que se asienta sobre los profesionales de la información y la comunicación. Según el paro registrado en el Servicio Público de Empleo Estatal, en septiembre de 2017 las mujeres representaban el 64\% de los periodistas parados, un porcentaje que, además, se ha mantenido por encima del 60\% desde 2008.

A esta situación de precariedad profesional, se sumó la exposición de la opinión pública a diversos casos de impacto mediático relacionados con los derechos de las mujeres, tanto a nivel nacional como internacional. El grueso de estos hechos estuvo relacionado con la violencia de género y las agresiones sexuales y su difusión se multiplicó gracias a diversas campañas de hashtivismo (Jimsook, 2017; Turley; Fisher, 2018).

Una de estas ciberacciones surgió a raíz de la etiqueta \#MeToo (Mendes; Ringrose; Keller, 2018), popularizada el 15 de octubre de 2017 por la actriz Alyssa Milano tras acusar de abuso sexual al productor de cine y ejecutivo estadounidense Harvey Weinsteina. Lo que hizo Milano fue visibilizar la indignación y animar a las mujeres a compartir en Twitter sus propias experiencias individuales para demostrar la naturaleza extendida de prácticas de abuso de poder, intimidación y violencia sexual. A esta iniciativa se sumaron celebridades del mundo del cine, la música, la ciencia y la política, que hicieron públicas las vivencias que habían sufrido en privado. El hecho de que mujeres popularmente conocidas se atrevieran a confesar la humillación, el maltrato, la intimidación y el chantaje vivido despertó un fuerte sentimiento de solidaridad e indignación entre mujeres que reactivó poderosamente la necesidad del feminismo, de estar unidas para responder y poner fin a estas actitudes machistas.

Si localizamos el malestar en España, entre 2016 y 2018 destacan tres casos de gran interés público y cobertura mediática, también relacionados con la violencia de género y las agresiones sexuales (Gutiérrez-Rubí, 2019; Bernal-Triviño, 2019):

- La desaparición a finales de agosto de 2016 de Diana Quer. De la joven, que regresaba a su casa de madrugada, se analizó su forma de vestir, comportamiento en redes sociales y anteriores relaciones con otros hombres y con familiares, lo que para colectivos feministas contribuyó a revictimizar a Diana en lugar de señalar al culpable.

- El caso de Juana Rivas, española residente en Italia que denunció a su pareja por malos tratos durante un viaje a Maracena (Andalucía) y se escondió con sus dos hijos pequeños con el fin de evitar que estos fueran devueltos con su padre, tal y como reclamaba la justicia italiana. En redes sociales colectivos de mujeres le mostraron su apoyo con el hashtag \#Juanaestaenmicasa y se convocaron concentraciones en varias ciudades.

- El caso de La manada, nombre con el que se conoce a la violación grupal que cinco hombres llevaron a cabo a una joven de 18 años en Pamplona en julio de 2016. El suceso, que fue considerado como un abuso sexual en la Audiencia Provincial y en el Tribunal Superior de Navarra, movilizó a gran parte de la población española que se manifestó durante 2018 y 2019 en desacuerdo con dichas sentencias. El caso fue finalmente revisado y sentenciado en junio de 2019 por el Tribunal Supremo, que lo consideró una agresión sexual.

Estos hechos han ocurrido de forma paralela en el tiempo a la expansión y democratización de las tecnologías de la información y la comunicación. La web, redes sociales y aplicaciones de mensajería instantánea:

- han actuado como fuentes de información (López; Muldoon; McKeown, 2019);

- han ayudado a la viralización de injusticias ejercidas contra mujeres de todo el planeta;

- han facilitado el compartir experiencias individuales de personas que hasta el momento no se identifican con el discurso feminista (Barker; Jane, 2016; Sassen, 2003);

- han permitido la autoorganización de colectividades (Sierra-Caballero, 2018, p. 982);

- han favorecido la creación del denominado "espacio público oposicional" al sistema (Negt, 2007).

En este marco, se han conformado como un emergente espacio de militancia política también para el activismo feminista (Sánchez-Duarte; Fernández-Romero, 2017).

Es así como en la segunda década del siglo XXI se ha configurado lo que ya se considera una nueva ola feminista (Knappe; Lang, 2014); esto es, una "conciencia social crítica frente a la desigualdad y la explotación económica y sexual de las mujeres" (Cobo, 2019). Su cuerpo vindicativo es la violencia sexual, lo que Cobo define como un mecanismo global "de control social que impide a las mujeres tanto apropiarse del espacio público como hacer uso de su autonomía y libertad" (Cobo, 2019, p. 138).

Para Cobo (2019, p. 134) "la magnitud de algunas de estas movilizaciones y el hecho de que se hayan producido en distintos continentes casi al mismo tiempo han convertido al feminismo en un movimiento de masas por cuarta vez en su historia". La nueva ola feminista sucede al movimiento sufragista (1848-1948), al feminismo radical de los años sesenta y setenta del siglo XX, simboliza-
En la segunda década del siglo XXI se ha configurado una nueva ola feminista, una conciencia social crítica frente a la desigualdad y la explotación económica y sexual de las mujeres 
do por el Movimiento de Liberación de la Mujer (MLM), y a la corriente de "feminismos en plural" que en la década de los 90 del siglo pasado planteaba, según Reverter-Bañón (2013, p. 458), "posibilidades de deconstrucción de los patrones identitarios" y alineados "con un sólo tipo de feminismo". En palabras de Reverter-Bañón (2013), "fruto de aquella reorganización de los discursos se multiplicaron los posicionamientos, los matices y las diferencias, idea que también recoge McRobbie (2009). Se empezó a hablar de feminismo filosófico, ecofeminismo o ciberfeminismo (Reverter-Bañón, 2013).

La británica Sadie Plant (1997), directora del Centre for Research into Cybernetic Culture de la University of Warwick (Inglaterra), acuñó el término ciberfeminismo refiriéndose al activismo feminista que encuentra en el ciberespacio nuevas formas de construir el sujeto y la identidad humana. Inserta dentro de la corriente que defiende el ciberfeminismo como utopía, también llamada netopia, Plant defiende, en palabras de Reverter-Bañón (2001, p. 39), "que la realidad virtual del ciberespacio puede acabar con la visión del mundo y la realidad material construida durante dos mil años por el orden patriarcal". Frente a ello está la visión de la realidad cibernética como una distopia, que entiende que "la cibercultura no sólo no ha cambiado los estereotipos de género, sino que incluso está sirviendo para acentuar más la dominación y opresión de las mujeres" (Reverter-Bañón, 2001, p. 41), dado que en la Red la sexualidad permanece (Springer, 1996; Núñez-Puente; Vázquez-Cupeiro; Fernández-Romero, 2016; Turley; Fisher, 2018) e incluso se han multiplicado las formas de ciberacoso.

Para De-Miguel y Boix (2002) lo que diferencia a la actual ola feminista es que ahora se trata de un "ciberfeminismo social", esto es, "un ciberfeminismo con una agenda de lucha política y de transformación social" (Reverter-Bañón, 2013, p. 456). Individuos desencantados se unen en el ciberespacio y forman redes o cibercomunidades, más allá de sus ideologías, filiaciones y opiniones. El ciberespacio les permite transformar el miedo en indignación en el momento que verbalizan y expresan su malestar y sus ideales en las redes sociales (Gil de Zúñiga; Huber; Strauß, 2018). El proceso se ha realizado al revés que en las anteriores olas feministas: se han conectado ideológicamente con las vindicaciones feministas, y ahora es cuando se están acercando a grupos feministas, ya organizados en unos casos y en otros recién constituidos (Cobo, 2019, p. 135).

Entre las mujeres que han dado apoyo a este reciente activismo feminista en España puede identificarse a un masivo grupo de profesionales de la información. Unidas por sus experiencias subjetivas (Bakardjieva, 2009, p. 92) en el ejercicio de la profesión, apuestan por autoorganizarse y visibilizarse juntas en la huelga del 8 de marzo de 2018 con la etiqueta \#lasperiodistasparamos. Este colectivo conforma el objeto de esta investigación, que se enmarca en los estudios sobre género y comunicación, así como en la teoría política feminista, que pretende reflexionar en torno a las posibilidades de establecer una crítica radical al poder desde las bases del feminismo y, en este caso, desde la profesión del periodismo.

Unidas por sus experiencias subjetivas, comunicadoras españolas apuestan por autoorganizarse y visibilizarse juntas en la huelga feminista del $8 \mathrm{M}$ como gremio afectado por el sistema

\subsection{El despertar de una conciencia gremial}

La nueva ola feminista es global, tecnológica, intergeneracional e intersectorial. Por primera vez, centenares de comunicadoras despiertan una conciencia gremial masiva por la igualdad de derechos en el seno de la profesión. No obstante, según indica Rovetto-Gonem (2013, p. 56), contamos con aportes teóricos sobre la participación de las mujeres en los escenarios de producción periodística desde 1970. En esta década "se institucionalizó en la mayoría de las disciplinas sociales y humanas la perspectiva de género como deriva del pensamiento feminista" (Lagarde, 1996). Desde entonces investigadoras de distintas áreas temáticas del campo de la sociología y de la comunicación han ofrecido "categorías de análisis y enfoques metodológicos novedosos".

En este sentido, Rovetto-Gonem detalla cómo "la sociología de la comunicación y la teoría de la comunicación de masas con enfoque de género han investigado la relación de los medios con la cultura, la significación de los mensajes en la construcción de la diferencia sexual, la identidad femenina y el sesgo de los estereotipos de género en la reproducción de la ideología dominante (Gallagher, 1979; Mattelart, 1982; Fagoaga; Secanella, 1984, entre otras)".

Por su parte la sociología de género se ha centrado en "el análisis del empleo femenino, la incorporación de la mujer en el mercado de trabajo y las transformaciones intrafamiliares (Borderías-Mondéjar; Carrasco-Bengoa; Alemany, 1994; Dema-Moreno; Díaz-Martínez, 2010)". Cabe citar aquí "la perspectiva teórica del newsmaking, interesada en las estructuras, las rutinas y la cultura profesional periodística (Wolf, 1987; Gallego, 1994; 2002); y los aportes provenientes de la sociología de la profesión periodística que observa aspectos como la identidad profesional (Ortega; Humanes, 2000), las condiciones y los roles en el trabajo (García-de-Cortázar; García-de-León, 2000)". En general los estudios mencionados han evidenciado la visión androcéntrica que predomina en la organización de las estructuras productivas y en los contenidos comunicativos (Larrondo-Ureta, 2005).

Rovetto-Gonem recuerda que fue en la Conferencia de Beijing (1995) cuando se otorgó "mayor visibilidad internacional al tema de las desigualdades entre mujeres y varones en todos los ámbitos de la vida como un problema de derechos". En este marco se identificó como elemento fundamental y originador de estas causas "el limitado acceso de las mujeres a los medios de comunicación y a las tecnologías de información, en términos de representación y de empleo". A partir 
de allí, algunas áreas de gestión política internacional propagaron la idea de que "las imágenes estereotipadas de las mujeres en las industrias mediáticas y su escasa participación como propietarias y productoras en los medios de comunicación son poderosas barreras que dificultan la universalidad de los derechos humanos (Chocarro, 2007; Chaher; Santoro, 2007)". Además se expuso la necesidad de estimular y reconocer las redes electrónicas y otras nuevas tecnologías aplicadas a la comunicación como medio para la difusión de información y de intercambio de ideas entre mujeres.

Asumiendo su compromiso ético con la sociedad, el activismo profesional ha generado desde principios de siglo numerosas iniciativas en aras de la igualdad de género mediante acciones organizadas para la denuncia de estereotipos en el relato de noticias. Por ejemplo, auspiciada por la Unesco, la organización periodística mexicana Comunicación e Información de la Mujer (Cimac) actúa desde hace 30 años a favor de una perspectiva de género. Y con este fin ha publicado un manual de buenas prácticas Hacia la construcción de un periodismo no sexista (Cimac, 2009) para un adecuado tratamiento de las noticias, en donde la mujer no aparezca por su condición.

Contando con el bagaje interpretativo expuesto aquí y ampliable a numerosas iniciativas, el objetivo de nuestro estudio es analizar los discursos de la cibercomunidad profesional gestada en torno al hashtag \#lasperiodistasparamos. El fin de esta investigación es:

- detectar la o las causas que han provocado esta conexión, especialmente digital;

- detectar las formas de interacción directa e indirecta entre las participantes;

- estudiar si este compromiso ha derivado en acciones políticas en el espacio real.

En base al marco teórico, se formulan cuatro hipótesis:

- La causa que ha motivado el surgimiento de una conciencia profesional feminista de comunicadoras es la indignación y, por derivación, la ira que provoca un contexto de indefensión profesional y de agresión sexual contra mujeres de todo el planeta. Al ponerlo en común a través de redes digitales, ello provoca que decenas de comunicadoras no sólo asuman el propio rol comunicativo en sus medios, sino que se impliquen también por primera vez como sujeto en el relato de su propia rabia.

- El principal canal de interacción directa de este colectivo es Telegram. Creado en un inicio como soporte para organizar y coordinar de forma horizontal su participación en la manifestación del $8 \mathrm{M}$, se ha convertido en un repositorio de actividades en la agenda mediática y de fuentes informativas con el propósito de facilitarles el trabajo de la comunicación con perspectiva de género.

- Twitter es el canal de visibilización y promoción al exterior de la movilización; es decir, a través del uso del hashtag \#lasperiodistasparamos ha pretendido conseguir un mayor grado de activación y sensibilización hacia la lucha igualitaria. También es una herramienta de influencia que ha permitido a las activistas alcanzar redes de personas que hasta el momento no se habían sentido identificadas con el feminismo. Asimismo, ha demostrado su utilidad para ejercer un papel dinámico de autorregulación, con interpelaciones directas a medios y colegas.

- El activismo digital ha provocado la creación de nuevas identidades políticas en la esfera del movimiento feminista. Se trata de asociaciones, plataformas y organizaciones profesionales feministas repartidas por toda España.

\section{Metodología}

Se ha llevado a cabo un análisis de los contenidos difundidos a través de Telegram y Twitter por parte de mujeres profesionales de la información y la comunicación con el hashtag \#lasperiodistasparamos.

Por lo que respecta al servicio de mensajería instantánea, se ha tenido acceso al canal "Las periodistas paramos". Como miembro, la aplicación permite el acceso a los mensajes enviados por las participantes desde el 28 de febrero de 2018 , cuando se creó, hasta el 20 de septiembre del mismo año, fecha en la que finalizó el estudio cuantitativo. La descarga del material multimedia compartido en este período ha sido de 1.891 fotos, 208 vídeos, 178 archivos, 12 audios, 4.642 enlaces y 27 mensajes de voz. El sistema de búsqueda de Telegram realiza exploraciones por palabras, fecha o nombre de la participante.

Por lo que se refiere al análisis del contenido divulgado en Twitter que incluye \#lasperiodistasparamos (Leavy, 2007), el estudio abarca el período comprendido entre el 28 de febrero de 2018, primer día en que se utilizó el hashtag, y el 20 de septiembre de 2018 , fecha en que como ya se ha indicado se decidió finalizar la recogida de datos. Para la obtención de estos tweets se ha hecho uso de un programa de código abierto que evita la limitación de búsqueda que Twitter impone a los programas que utilizan API. Este programa simula las peticiones que el usuario realiza a Twitter cuando busca un hashtag. Una vez recopilados todos los tweets, estructura la información en un archivo CSV con las siguientes categorías: nombre de la cuenta, fecha, texto, retweets, favoritos, menciones, hashtags y link al tweet. Con esta técnica se han obtenido 13.163 tweets publicados en el período indicado.

A partir de dicha información, el estudio ha querido observar a través de la estadística inferencial el perfil de las cuentas más activas, los tweets más retweeteados y favoritos, las menciones más frecuentes y los hashtags más utilizados, además del vinculante. Se ha utilizado también la aplicación Trendinalia para conocer el posicionamiento del hashtag en los dos períodos de mayor uso en todo este periplo:

- la primera y segunda semanas de marzo de 2018, cuando se convocó la huelga general de mujeres;

- la primera semana de junio, momento en que se celebró la primera asamblea de comunicadoras feministas en Madrid. 
La muestra se complementa con la información publicada en el blog "Las periodistas paramos", donde se incluyó el formulario de adhesión al movimiento, así como las cuentas creadas en otras dos redes sociales: Facebook (@lasperiodistasparamos) e Instagram (@lasperiodistas).

https://lasperiodistasparamos.wordpress.com

Por último, se han realizado 20 entrevistas en profundidad semi-estructuradas:

- a las creadoras de las cuentas de Twitter más activas con el hashtag \#lasperiodistasparamos (Marta Pastor, María José Romero, Rosa Tristán, Merche Camacho, Maribela Gutiérrez, Prado Campos, Carmen Torres, Patricia Pages y María Grijelmo);

- a periodistas que han tenido un papel protagonista en el impulso de iniciativas tanto digitales como políticas dentro de esta cibercomunidad (Marilín Gonzalo, Ana Reviejo, Pilar Almenar, Anna Gimeno, Remei Castelló, Noelia Ramírez, Cristina Fallarás y Mercedes Domènech);

- a las participantes en la jornada Periodistas Feministas. ¿Cuál es nuestro papel?, organizada en febrero de 2019, a las puertas de una nueva huelga general. Se reunió a varias activistas con diferentes roles en este movimiento para debatir sobre los éxitos conseguidos por este activismo profesional (Anna Gimeno-impulsora del colectivo que aglutina a mujeres periodistas feministas en la Comunidad Valenciana, Les Beatrius-; Mercedes Domènech -ex coordinadora del grupo de Telegram-; Ana-Isabel Bernal-Triviño -investigadora de la Universitat Oberta de Catalunya y activista feminista con conocimiento de las redes sociales-; Cristina Fallarás -impulsora del movimiento \#Cuentalo-; Remei Castelló -miembro de Les Beatrius y miembro de la Comisión de Comunicación de la Asamblea Feminista 8M Valencia-; Ana Reviejo -miembro de Colombine, plataforma de mujeres periodistas feministas de la Región de Murcia-; Isabel Cadenas -miembro de la Comisión de Comunicación de la Asamblea Feminista 8M Madrid-y Emilia Bolinches -representante de Les Beatrius en la Red Estatal de Comunicadoras Feministas-).

Dada su implicación y conocimiento del movimiento, se ha pretendido identificar y analizar las causas y efectos de esta colectividad feminista, así como detectar los temas que generan controversia dentro del grupo. Para ello se ha utilizado Atlas/ti, programa que permite analizar conceptualmente las citas textuales.

\section{Resultados}

\subsection{Indefensión e indignación, imanes de esta colectividad}

El 26 de febrero de 2018 se reunieron en Madrid alrededor de cincuenta periodistas para planificar su participación como colectivo profesional en la huelga feminista del 8M en España. La reunión fue impulsada por Marilín Gonzalo, quien en aquel momento escribía un libro sobre la desigualdad que padecen las mujeres en la profesión y disponía del contacto de diversas comunicadoras a las que había entrevistado:

"Durante semanas estuve compartiendo con ellas cuáles eran los obstáculos que nos encontrábamos en nuestras carreras: techo de cristal, brecha salarial, precariedad y acoso sexual, entre otros. A raíz de la convocatoria oficial de la huelga del $8 \mathrm{M}$ promoví un encuentro para manifestarnos como colectivo. Habían confirmado su asistencia una veintena de mujeres de la profesión. Pero al final el mensaje llegó, a través de correos y mensajes de WhatsApp, a 50 mujeres que acudieron a aquel bar del barrio de Malasaña que acabó cediendo el sótano. Mientras hablábamos, vimos que teníamos las mismas inquietudes, que habíamos experimentado las mismas situaciones en nuestros trabajos" (Marilín Gonzalo).

Paralelamente, en aquellas mismas fechas Anna Gimeno, periodista y activista feminista, incentivó un encuentro físico de varias periodistas valencianas:

"Llamas a una compañera, a una amiga. Tejimos una red de indignación y rabia ante la inseguridad laboral y los abusos contra las mujeres que es la que nos ha dado el soporte que nos permite hacer muchas cosas" (Anna Gimeno).

Respecto a los medios de organización y comunicación, se buscaron canales que permitieran acoger a decenas de profesionales que quisieran estar conectadas con esta iniciativa profesional. Marilín Gonzalo creó el 28 de febrero de 2018 un grupo de Telegram Ilamado "Las periodistas paramos" e hizo público el enlace de acceso. Mercedes Domènech, responsable de revisar las identidades de los miembros del chat y de eliminar cuentas de hombres, bots y trols, explica:

"Nos incluimos en ese grupo unas a otras, siendo el mínimo denominador común mujeres que trabajábamos en medios. Más allá de la ideología que tuviéramos, todas queríamos realizar esa lucha. Las más conservadoras se sumaron porque ellas también tenían obstáculos y se encontraban con un techo de cristal. Las luchas eran distintas, partíamos de puntos distintos, pero de repente nos encontramos en un chat todas" (Mercedes Domènech).

El 1 de marzo, a las 11:11 horas, se informó en el grupo de Telegram que se estaba elaborando un formulario de adhesión a un manifiesto. El texto se consensuó entre las convocantes de la reunión de Madrid y el grupo de periodistas valencianas, quienes ya habían puesto en marcha a nivel regional el manifiesto Periodisme sense masclisme. El grupo organizador de la capital y por ende del grupo estatal lo conformaron:

- Marilín Gonzalo, desocupada en aquel momento;

- Ana Requena, de eldiario.es; 
- Marta Borrás, corresponsal de EFE en Bruselas;

- Magda Bandera, directora de La marea;

- Eva Belmonte, de la fundación ciudadana Civio, organización independiente y sin ánimo de lucro que trabaja para lograr transparencia en las instituciones.

A ellas se sumaron días más tarde Amaya Larrañeta, de 20 minutos, y Mercedes Domènech, coeditora de informativos en La sexta.

\section{2. \#lasperiodistasparamos, la firma de presentación y la visibilización en redes sociales}

Se decidió visibilizar las deliberaciones y acuerdos que tenían lugar dentro de Telegram, plataforma de mensajería instantánea. Se determinó hacerlo en Twitter mediante cuentas personales y de colectivos profesionales. El hashtag que conectaba estos contenidos era el consensuado, \#lasperiodistasparamos.

Del estudio de esta red, se extraen diversos resultados. La primera repercusión de \#lasperiodistasparamos tuvo lugar la tarde del 1 de marzo, cuando a partir de las 16:19 horas, mujeres periodistas comenzaron a pedir el apoyo al manifiesto a través de Twitter y compartieron material multimedia generado por las participantes.

El hashtag alcanzó aquel día su primer eco en Twitter, llegándose a situar en la posición 49 de trending topics en España, al establecerse como \#TT durante 5 horas y 55 minutos. En este primer día, en el que se produjo la primera adhesión masiva de periodistas al manifiesto, el tweet de mayor éxito fue el de la periodista e investigadora Ana Bernal-Triviño:

“Compañeras periodistas!! Nosotras paramos el \#8M en la huelga feminista. Tenemos mucho que pedir y mejorar en nuestra profesión. $Y$ nuestras voces tienen que ser una. Firma y difunde este manifiesto porque \#lasperiodistasparamos ya somos 800!! https:// lasperiodistasparamos.wordpress. com/"

https://twitter.com/anaisbernal/ status/969240121676574721

La cuenta de Bernal, con 31.000 seguidores en el momento de la investigación, consiguió 461 retweets y 734 me gusta.

La incorporación progresiva de participantes en el canal de Telegram se multiplicó por cuatro en dos días y a un ritmo superior creció el listado de periodistas que iban firmando digitalmente al manifiesto. Finalmente se decidió

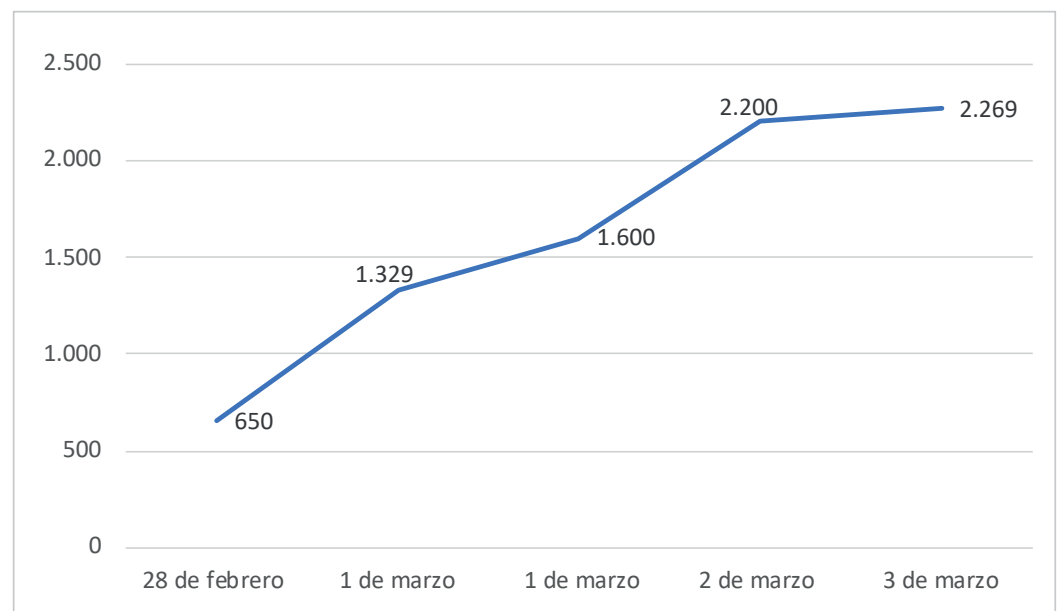

Gráfico 1. Evolución de seguidoras en el canal de Telegram "Las periodistas paramos" desde las 14:05 del 1 de marzo a las 11:15 del 3 de marzo.

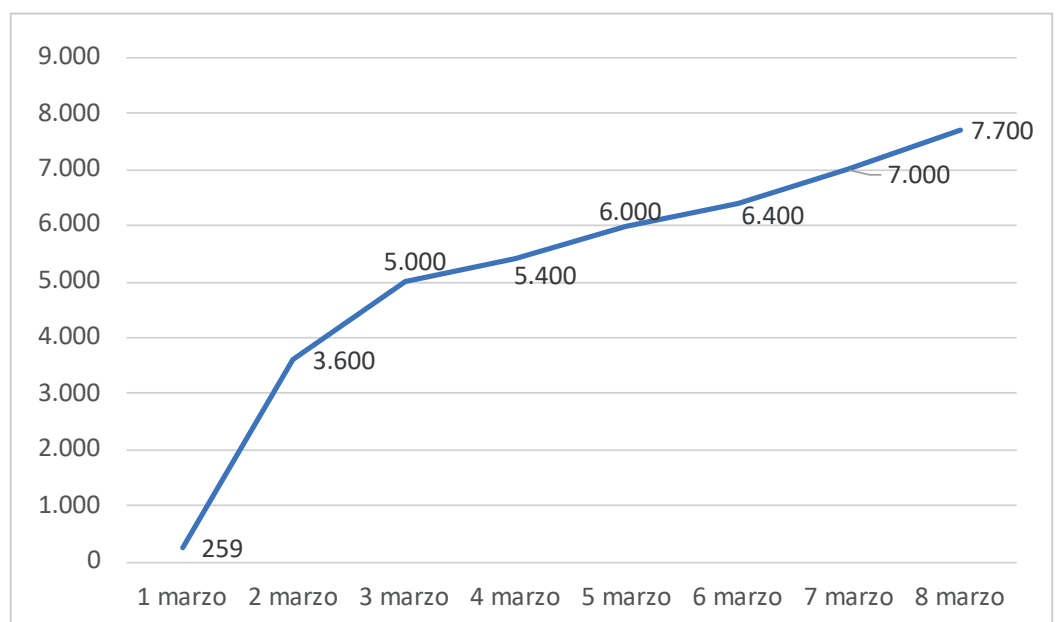

Gráfico 2. Evolución de las comunicadoras que se adhieren al manifiesto de "Las periodistas paramos" desde el 1 al 8 de marzo.

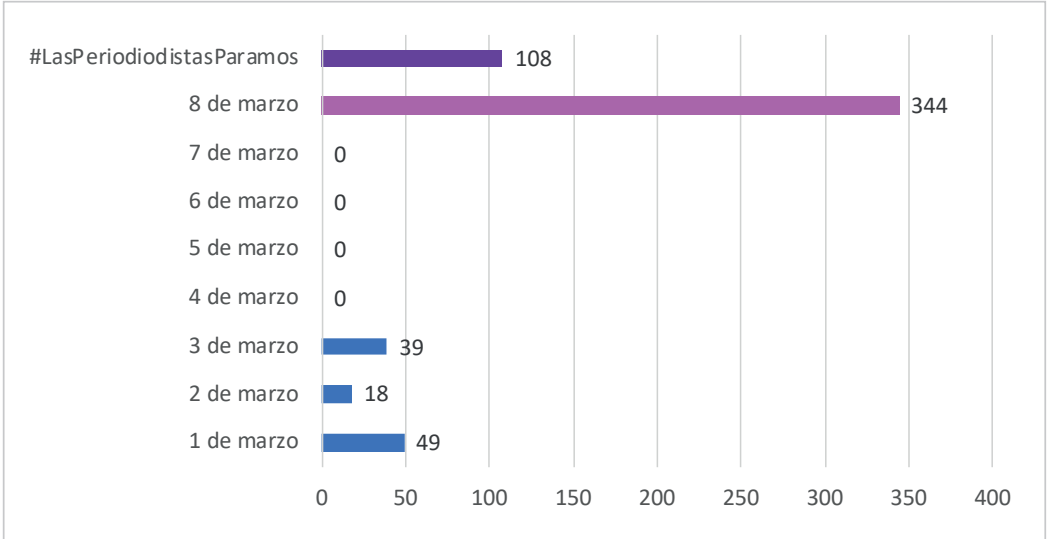

Gráfico 3. Posición del hashtag \#LasPeriodistasParamos en el ranking de trending topics en España.

Fuente: Trendinalia 
eliminar el requisito de que los nombres de las firmantes tuvieran que vincularse a una empresa para evitar represalias de las personas responsables. En ocho días el número de mujeres que firmaron el texto se multiplicó por 30, de 259 a 7.700 .

Hasta el día de la huelga el hashtag \#lasperiodistasparamos vivió en Twitter una evolución similar a la del crecimiento de firmantes del manifiesto, siendo los días de mayor actividad el 1, 2 y 3 de marzo.

Durante la jornada de la huelga ocurrió algo anecdótico: según Trendinalia, 79 tweets con el hashtag mal escrito -\#lasperidiodistasparamos- (retweeteado, entre otras, por una cuenta líder, la cuenta personal de la periodista televisiva Ana Pastor) lograron colocarlo como trending topic del día, incluso 236 puntos por encima de la etiqueta oficial del grupo.

Son 9 los tweets que fueron retweeteados al menos 1.000 veces en el período analizado. Todos ellos se publicaron el día de la huelga general, momento de mayor sensibilización. Como era previsible, la mayoría fueron generados por cuentas de periodistas, medios y asociaciones que suman miles de seguidores. No obstante, llama la atención el hecho de que el primer y tercer tweet más retweeteados fueron escritos por la periodista del semanario S Moda Noelia Ramírez, precisamente la que menos seguidores tenía entre las autoras de estos tweets.

El contenido publicado por Ramírez sumó el mayor apoyo en la Red, tanto de las comunicadoras feministas como del ciberfeminismo en general. Apelaba a un tema de máxima irritación en el movimiento como son las dificultades de conciliación y corresponsabilidad de las profesionales que deciden ser madres. Noelia lo abordó desde la experiencia personal y como réplica al director de un medio de comunicación, La razón.

El texto contiene la reacción de Ramírez a un tweet de Francisco Marhuenda, en el que calificaba la huelga de "un poco pija" y a las huelguistas de "mujeres que no han tenido ningún problema serio en su vida". Al respecto, Ramírez explica:

"No solía tweetear mucho y en ese momento no tenía apenas seguidores, no soy de contestar ni nada. Pero con toda la fuerza del chat de Telegram en aquel momento te vienes arriba. Yo trabajé cinco años en La razón y me dio mucha rabia leer sus palabras. Lo mío fue una cosa inesperada y se viralizó" (Noelia Ramírez).
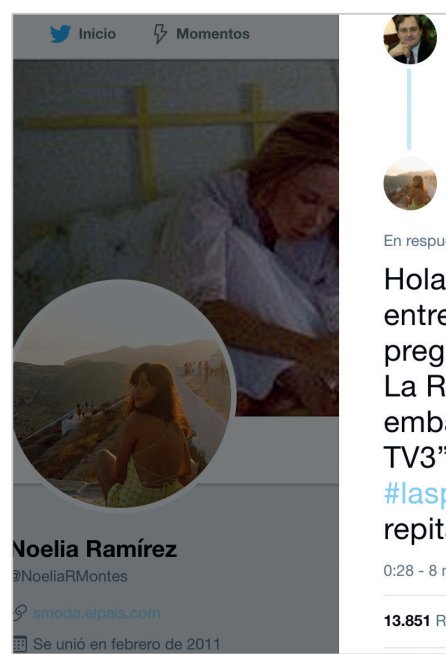
problema setro en su vida. Jamás he visto en una redacción que se discrimi

○ $856 \quad €\urcorner 450 \quad \bigcirc 900$

Noelia Ramírez

Hola, Paco: Recuerdas cuando me entrevistaste para trabajar (sin contrato) y me preguntaste si tenía novio para añadir que en La Razón no nos podíamos quedar embarazadas porque "esto no es como TV3"? Eso es discriminación. Hoy \#lasperiodistasparamos para que no se repita. Saludos

$0: 28$ - 8 mar. 2018

13.851 Retweets 20.189 Me gusta 10060

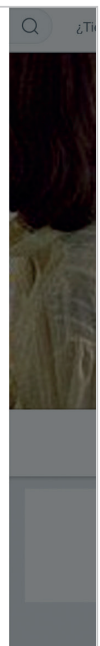

Imagen 1. Tweet con el hashtag \#LasPeriodistasParamos que sumó mayor número de retweets y ‘me gusta'

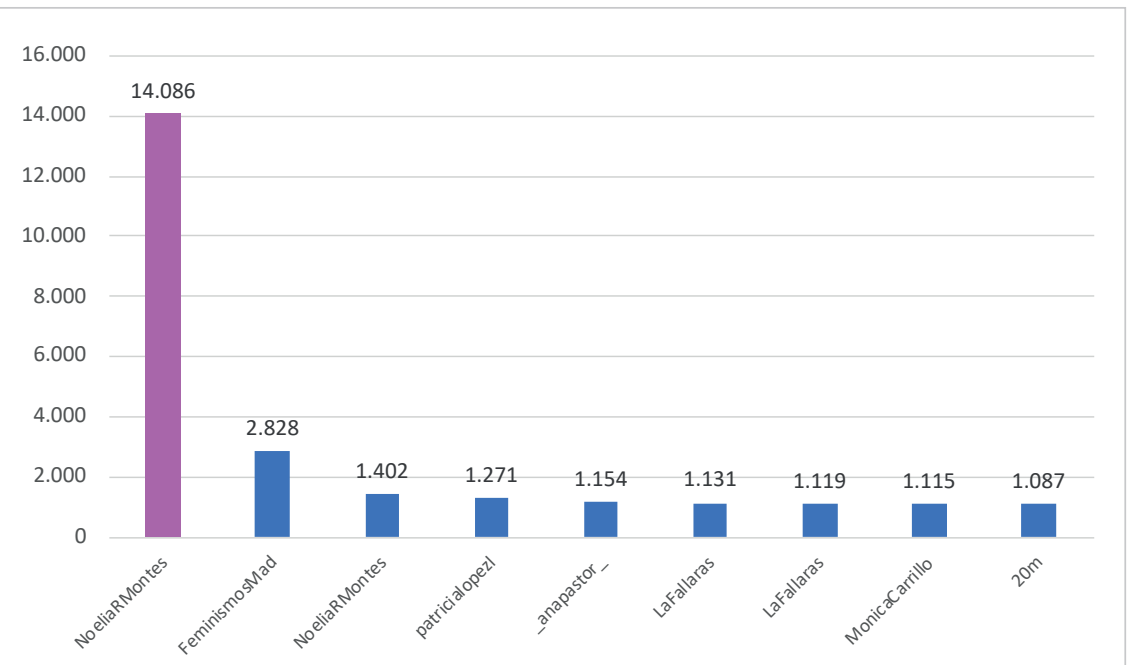

Gráfico 4. Tweets con el hashtag \#LasPeriodistasParamos con más retweets

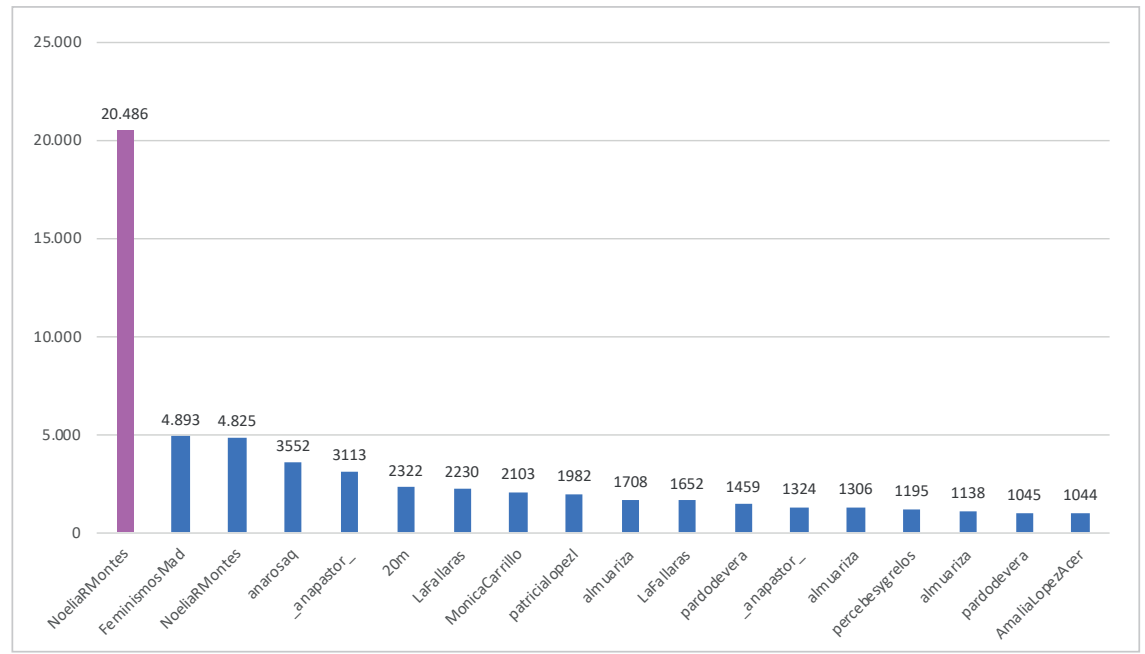

Gráfico 5. Tweets con el hashtag \#LasPeriodistasParamos con más favoritos
Fancisco Marnuenda - epacomarhuenda $\cdot /$ mar. 2018 Esta huelga es un poco pija. De muchas mujeres que no han tenido ningún 


\subsection{La fuerza de los medios de comunicación de masas}

El segundo tweet más retweeteado fue de la cuenta organizadora de la huelga en Madrid (@Feminismos_ Mad) y el resto fueron escritos por cuatro periodistas televisivas:

- Patricia López, periodista de Público y tertuliana en diversas cadenas, criticaba la actitud de la líder de Ciudadanos, Inés Arrimadas;

- Ana Pastor, directora de El objetivo en La sexta, publicó una foto de la concentración en la Plaza de Callao de Madrid;

- Cristina Fallarás, escritora y periodista, aplaudió el primer acto colectivo de la profesión y recordó su despido tras quedarse embarazada;

- Mónica Carrillo, periodista y escritora, subrayó el orgullo que sentía por aquella movilización.

Si se observan las menciones más frecuentes en el contenido publicado en Twitter, éstas se refieren a diarios progresistas que concedieron espacio informativo a la movilización feminista de las comunicadoras. Se trata de contenidos publicados por eldiario.es, El país, La SER y La marea. Los medios de comunicación señalados son precisamente las empresas en las que trabajan algunas de las periodistas más implicadas en el movimiento profesional.

Por último, las cuentas más activas con el hashtag estudiado ${ }^{b}$, fueron las de:

- Marta Pastor, directora y presentadora del programa Ellas pueden de Radio 5;

- María José Romero, periodista de La FM, medio digital de Cádiz;

- Rosa Tristán, colaboradora en diversos proyectos medioambientales después de trabajar 22 años en el diario El mundo;

- Merche Camacho, redactora de Lanza digital, diario digital de Ciudad Real;

- Maribela Gutiérrez, colaboradora en medios de agricultura, medio ambiente y artes escénicas.

Todas ellas se definen como activistas feministas desde hace años y tienen una trayectoria de participación política en el movimiento feminista continuado en el tiempo. Aseguran que las redes sociales, de las que son usuarias asiduas, "son un elemento de autoexpresión y de lucha contra las agendas políticas y mediáticas". Profesionalmente ninguna se encontraba en una situación de inestabilidad laboral o de riesgo de pérdida del trabajo por expresar sus ideas feministas. Todas ingresaron en el grupo de Telegram desde los primeros días, donde se mostraron participativas.

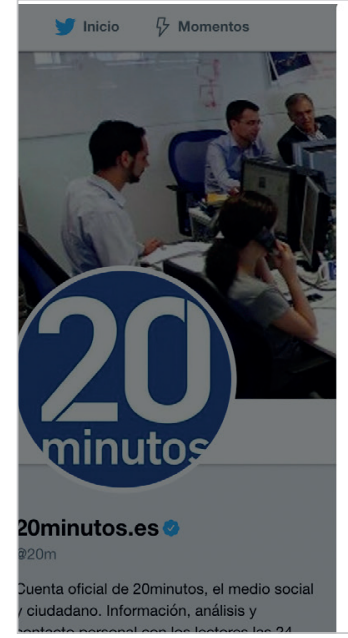

20 20minutos.es

Varias mujeres se desnudan ante la catedral de San Sebastián como protesta contra su obispo, que relacionó a las feministas con "el demonio" ver.20m.es/93rs93 \#8deMarzoHuelgaFeminista \#LasPeriodistasParamos \#Huelga8Marzo

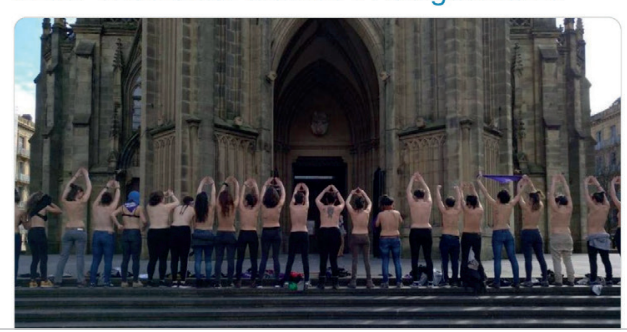

\#LasPeriodistasParamos

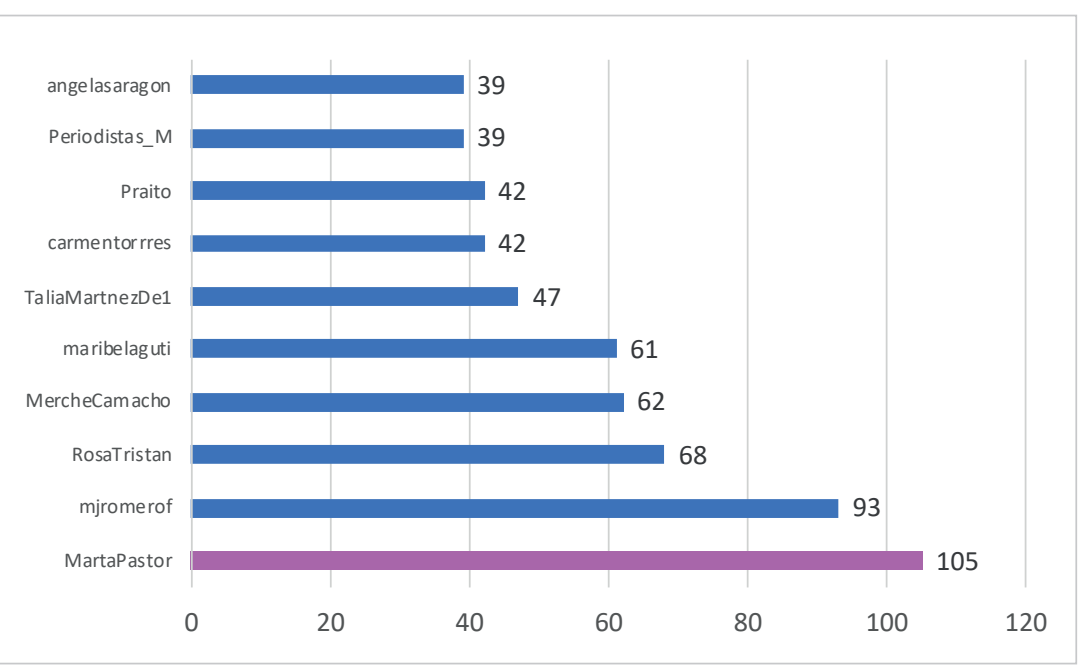

Gráfico 6. Número de tweets generados por las cuentas más activas con el hashtag \#LasPeriodistasParamos

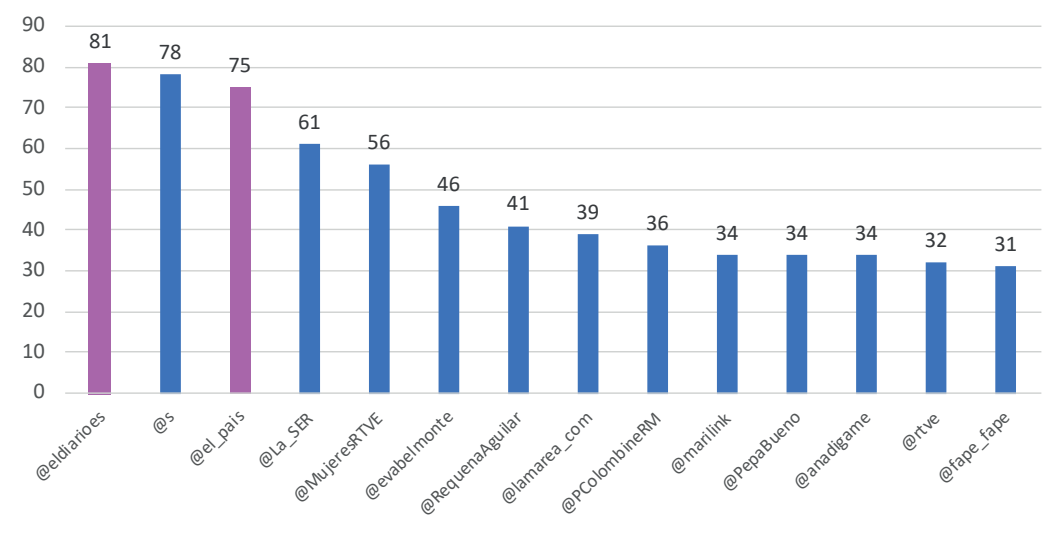

Gráfico 7. Cuentas de Twitter más mencionadas en los tweets que contienen \#LasPeriodistasParamos ${ }^{c}$ 
“El 8M es una creación fruto de varios componentes. Un año antes se ha producido un hartazgo brutal. Había desánimo porque las feministas no hemos avanzado. Hemos hecho unas leyes, sí, pero son normas muy recomendatorias, no obligan. $Y$ este hartazgo, que es una sensación muy mala, lleva a la desesperación, y la desesperación lleva a la rebelión en la mayor parte de las cosas" (Marta Pastor).

María José Romero apunta:

"Conseguimos aupar el hashtag a los primeros trending topics aquellos días. Sabíamos cómo hacerlo y nos dimos indicaciones para hacer aflorar aquellos días los puntos del manifiesto. Esta estrategia nos dio visibilidad".

Prado Campos argumenta:

“Me impliqué desde el primer momento porque el hecho de estar unidas, más allá de colores, por defender algo que es nuestro, que son nuestros derechos y libertades, me interpeló básicamente. Que en un colectivo tan disperso se formara un bloque tan unido, fue una señal muy fuerte que se envió a la sociedad. Hemos conseguido poner en la agenda política un debate que no estaba, hemos dado un golpe en la mesa, hemos dicho estamos aquí y no nos vamos a callar. Ahora falta muchísimo por hacer".

\subsection{Las redes paralelas, un mero repositorio}

El movimiento también se sirvió de manera colateral de otras dos redes, que actuaron a modo de repositorio:

- Facebook (@lasperiodistasparamos),página creada el 6 de marzo de 2018;

- Instagram (@lasperiodistas).

En la página de Facebook se publicaron los contenidos que se comparten en el grupo de Telegram, especialmente enlaces a noticias, y se mantuvo actualizada hasta noviembre de 2018. Mientras tanto, Instagram se utilizó como repositorio de 64 imágenes que resumen el período comprendido entre el inicio de las reivindicaciones, con el diseño del logo identificativo creado por la ilustradora Elsa Reig, hasta el 10 de marzo de 2018; es decir, pasada la huelga general, no se ha mantenido actualizado. Por lo que respecta a la web del movimiento, se trata de un contenido sin navegación por páginas que se limita a recoger el manifiesto y las personas suscritas.

\subsection{La desvirtualización}

Tras este clímax mediático que supuso el 8M, no es hasta junio de 2018 cuando se localiza un nuevo punto de interés del hashtag que estudiamos, ocupando la posición 23 entre los TT en España. Coincide con la asamblea organizada el 2 de junio en el auditorio Marcelino Camacho de Madrid para desvirtualizar el movimiento y conocer las iniciativas concretas que diferentes grupos autonómicos están programando o llevando a cabo para visibilizar y reivindicar el papel de las mujeres en la profesión.

Este encuentro reunió a cerca de 200 profesionales, es decir, a un 20\% de las participantes en el ciberespacio. Sirvió para poner rostro a las nuevas organizaciones surgidas de este ciberactivismo, grupos de trabajo que se distribuyen a nivel autonómico (tabla 1). Además se configuró: 
- un grupo lobby, para presionar a las instituciones con representantes de los grupos territoriales;

- un grupo de lenguaje inclusivo;

- un grupo jurídico encargado de estudiar la mejor forma de organización de las periodistas, analizando las diferentes plataformas.

Tabla 1. Organizaciones profesionales de comunicadoras feministas surgidas a raíz del ciberactivismo \#lasperiodistasparamos

\begin{tabular}{|c|c|}
\hline Nombre & CCAA \\
\hline Xornalistas Galegas & Galicia \\
\hline Periodistas Feministas de Granada & Granada \\
\hline Asociación de Periodistas por la lgualdad & Aragón \\
\hline Plumas Moradas & Bruselas \\
\hline Xarxa de Periodistes i Fotoperiodistes Valencianes (Les Beatrius) & Comunitat Valenciana \\
\hline Asociación de Periodistas Feministas de Castilla y León & Castilla y León \\
\hline Asociación de Periodistas Feministas de Navarra & Navarra \\
\hline Periodistes Feministes & Catalunya \\
\hline Vivas. Mujeres Canarias de la Comunicación & Canarias \\
\hline Colombine & Murcia \\
\hline Comunicadoras $8 M$ & Estatal \\
\hline Red Internacional de Mujeres Periodistas y Comunicadoras & Estatal \\
\hline Mujeres RTVE & Estatal \\
\hline Asamblea de Mujeres Periodistas de Málaga & Málaga \\
\hline Comfem & Baleares \\
\hline
\end{tabular}

Si se atiende a las acciones políticas que se han llevado adelante desde marzo a diciembre de 2018, cabe enumerar:

1) Cambios en las rutinas productivas de medios de comunicación:

- Diarios españoles cuentan con una nueva sección de Género o Igualdad, al frente de las cuales se coloca una mujer. El primero en crearla fue El país (mayo 2018), poniendo al frente de una nueva corresponsalía de Género a la periodista Pilar Álvarez; le sigue en septiembre de 2018 eldiario.es, nombrando a la periodista Ana Requena redactora jefa de Género.

- RTVE nombró en octubre de 2018 a dos editoras de Igualdad para velar por los contenidos en TVE y RNE, respectivamente: Alicia G. Montano ${ }^{d}$ y Paloma Zamorano

- Constitución de agendas/censos de expertas por parte de diversos organismos (por ejemplo, la Asociación de Mujeres Investigadoras y Tecnólogas), además de las que, a nivel individual, se comparten en el grupo de Telegram cuando alguien solicita a expertas en un tema.

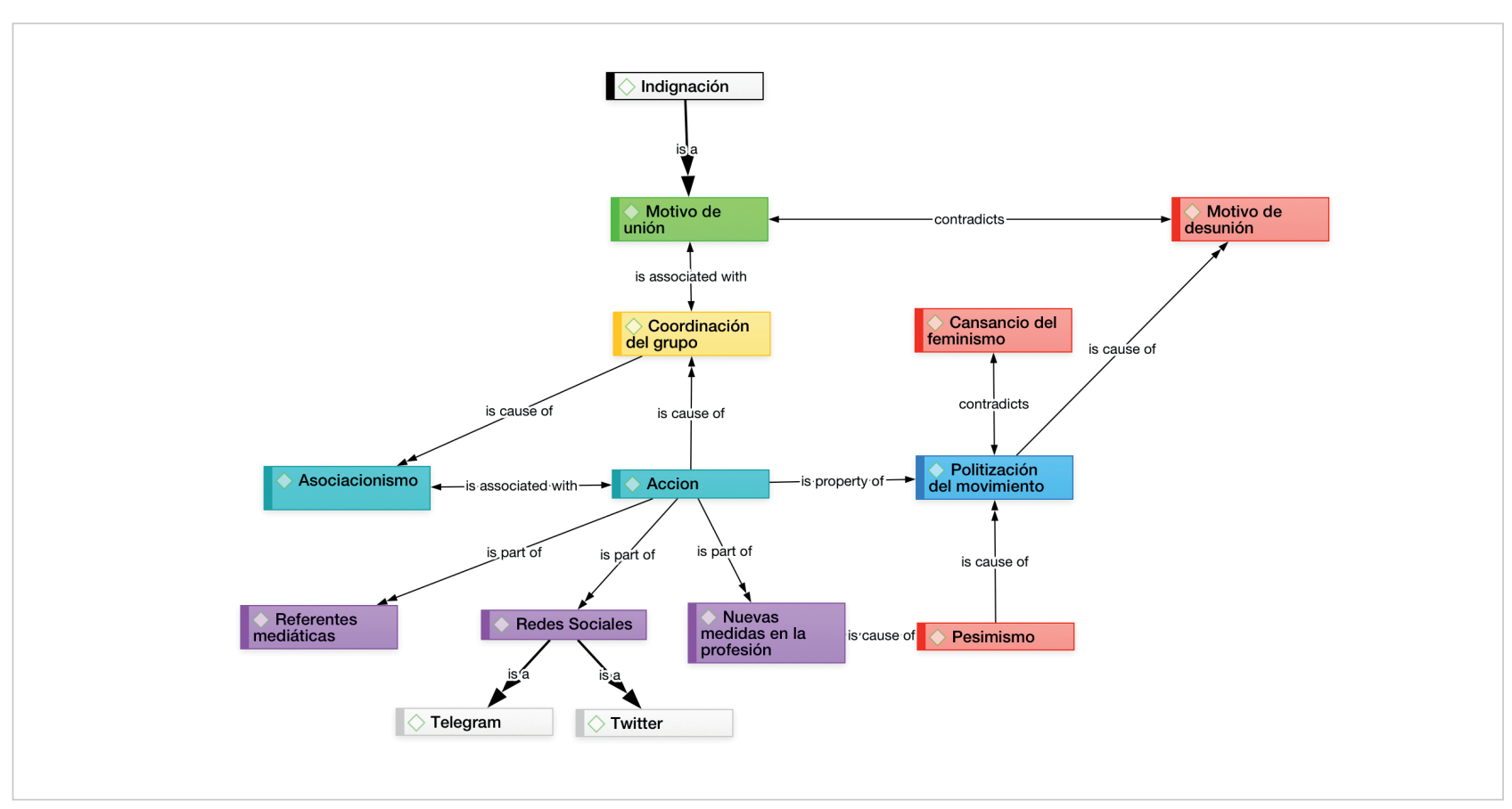

Imagen 4. Esquema visual de los principales códigos extraídos en las entrevistas en profundidad. Fuente: Atlas.ti 
- Se programan espacios dedicados al feminismo, como el programa radiofónico que María José Romero, una de las activistas de \#lasperiodistasparamos, estrenó en noviembre de 2018 en La FM con el objetivo de desmontar tópicos y bulos sobre feminismo.

2) Cambios en la organización profesional:

- Nacimiento de nuevas asociaciones profesionales de periodistas feministas.

- Creación de una bolsa de trabajo (Las periodistas no paramos) gestionada desde una página de Facebook. En la asamblea de junio se decidió compartir y difundir ofertas de trabajo y oportunidades remuneradas (concursos, becas...) para todas las mujeres que se dedican al mundo del periodismo y/o la comunicación.

3) Cambios en la autorregulación:

- Redacción de manuales para el tratamiento mediático de la violencia de género (por ejemplo, el Manual de estilo para el tratamiento de la violencia machista y el lenguaje inclusivo en los medios de comunicación de la Unió de Periodistes Valencians, redactado por las periodistas Remei Castelló y Anna Gimeno)

- Uso de las cuentas de Twitter de las organizaciones profesionales feministas para ejercer una autorregulación dinámica, mencionando a medios y periodistas ante la falta de deontología de sus piezas informativas; o bien para aplaudir iniciativas periodísticas con perspectiva de género.

Visto este movimiento profesional feminista con perspectiva, prácticamente un año después de su gestación y a un mes vista de una nueva huelga general con motivo del 8 de marzo de 2019, se registraron voces críticas con el optimismo que se desprende tras esta conciencia de clase profesional. Las razones en las que se apoyan algunas activistas para exigir una mayor acción política son:
Por primera vez a nivel masivo en España se ha configurado una colectividad de mujeres profesionales que toman conciencia de clase como periodistas y/o comunicadoras feministas

- La no consecución de mejoras laborales. La escritora y periodista Cristina Fallarás critica:

"Lo laboral significa dinero, producción, puestos de trabajo y contratos, por lo que creo que ningún periódico en este país, ninguna radio ni ninguna televisión pueda decir que después del $8 \mathrm{M}$ eso haya mejorado, y ha pasado un año desde la movilización".

- El acceso de las mujeres a puestos de poder no garantiza una visión feminista del periodismo.

"Creo que el machismo es tan estructural que muchas mujeres son machistas y no lo saben siquiera, incluso defienden que son feministas",

apunta la periodista e investigadora Ana Bernal-Triviño (2019), quien critica la aparición de noticias sin perspectiva de género en los medios que cuentan ahora con responsables de garantizar esta cobertura.

- “¿Se puede hacer un periodismo feminista en medios de comunicación vendidos al sistema capitalista, que dependen de la publicidad y de un tejido industrial en el que el cuerpo de la mujer es rentable?", se pregunta la periodista Anna Gimeno:

"Es que no sólo estamos hablando de que hay una ideología machista, que son una serie de creencias machistas que nos están perjudicando y en las que está todo atrapado, es que estamos hablando de que cosificar a la mujer es muy rentable. De momento, no hemos sacado esos temas de la agenda mediática y se han sustituido por noticias sobre bienestar, emociones, cuidados [...] No se trata de levantar la alfombra y limpiar lo que hay debajo, es que a lo mejor hay que tirar la alfombra".

- En el seno del grupo de Telegram se constata la existencia de dos temas conflictivos que dividen al grupo: la prostitución y los vientres de alquiler.

"Cuando se reflexiona sobre ellos en el grupo digital, se pierde el diálogo y comienzan las duras críticas entre las participantes, que rozan la injuria, y que son la causa del abandono del grupo. Son decenas de periodistas las que se han marchado" (Mercedes Domènech).

- La globalización de esta cuarta ola feminista

"ha provocado en la Red una respuesta virulenta de discursos antifeministas, que deriva en múltiples formas de ciberacoso y que afectan, en nuestro caso, a periodistas feministas activas en redes" (Remei Blasco).

\section{Conclusiones y discusión}

Por primera vez a nivel estatal y masivo en España se ha configurado una colectividad de mujeres profesionales que toman conciencia de clase como periodistas y/o comunicadoras feministas, tal y como puede extraerse de los términos más repetidos en los contenidos analizados (imagen 5). Se trata de un colectivo profesional que, más allá de sus diferencias de edad e ideológicas, se han unido para decir no al machismo que impera en su profesión y en la sociedad en general. En síntesis, es un movimiento de reconocimiento propio (ser, soy, eres). Y como asociación, tiene una misión ética y deontológica: conseguir que la igualdad entre géneros sea una realidad en su trabajo y en los contenidos con los que los medios influyen en la opinión pública. 
Los contenidos analizados y las entrevistas realizadas validan la hipótesis planteada sobre la causa que genera esta red de periodistas feministas, tejida en España a raíz de un sentimiento de empoderamiento surgido del hartazgo (Ekman; Amna, 2012), la indignación, la superación del miedo y la denuncia compartida ante la opinión pública de actitudes y perspectivas machistas en su profesión (Woltersdorff, 2011; Baer, 2016): brecha salarial, techo de cristal, dinámicas de trabajo basadas en el presentismo y la libre disposición, acoso sexual y laboral, espacios de opinión masculinizados y enfoque androcéntrico de los temas, tal y como denuncian en su manifiesto. La apelación a los sentimientos consigue la conciencia que hasta el momento no habían logrado los datos publicados por el Instituto Nacional de Estadística o la Federación de Asociaciones de Periodistas de España $(F A P E)$, entre otros organismos. Por tanto, como ya ocurrió con el 15M, es un movimiento más expresivo que instrumental en la fase inicial (Castells, 2015).

Esta red, como otros movimientos sociales de principios del siglo XXI, comenzó a hilarse desde pequeños círculos de amistad establecidos en el espacio físico; no obstante, el gran crecimiento de participantes se produjo cuando se hizo uso de dos redes digitales para organizarse y comunicarse:

- Telegram, una aplicación de mensajería de acceso abierto que permite que en una conversación entren miles de participantes, al tiempo que genera un repositorio de todos los archivos compartidos;

- Twitter, donde el llamado hashtivismo feminista consiguió visibilizar con \#lasperiodistasparamos el movimiento de concienciación profesional. Gracias a sus características comunicativas -inmediatez, simplificación del mensaje y abaratamiento de la difusión-, Twitter destaca por su capacidad para expandir los mensajes y crear comunidades de afinidad ideológica (Arroyas-Langa; Martínez-Martínez; Berná-Sicilia, 2018).

Esta sororidad digital (Fotopoulou, 2014) demuestra que Twitter puede ser utilizado para viralizar una protesta social puntual -como fue la huelga general- a través del posicionamiento temático de etiquetas asociadas al evento en cuestión. Se sostiene aquí la teoría de que los servicios de redes sociales refuerzan la visibilidad de nuevos activismos (Diani, 2000; Van-Aelst; Walgrave, 2002). En este caso este potencial queda reforzado por la habilidad comunicativa de las usuarias, expertas en estrategias discursivas propias del canal de comunicación (menciones, hashtags, imágenes y videos adjuntos, enlaces, retransmisiones en directo).

Sin embargo, el empleo del hashtag como estrategia para la búsqueda de una visibilidad global acaba deviniendo en la preponderancia de un tipo de discurso donde predomina la emisión sobre la interacción diádica y donde el debate tiende a reducirse al intercambio de retweets de apoyo o denuncia ante una red de contactos predominantemente afines. Este tipo de dinámicas favorecen el agrupamiento frente a la cooperación y el debate entre visiones diferentes acerca del feminismo y su agenda de prioridades (Caro-Castaño, 2015). Por tanto, si bien esta red ampliamente usada por periodistas (Rodríguez-Ruibal; García-López, 2013; López-Meri, 2015) ayuda a visibilizar la movilización, no es un escenario de construcción de consenso o de transformación de imaginarios preconcebido (Giraldo-Luque; Fernández-García; Pérez-Arce, 2018).

A ello se añade el peligro de la centralización en internet (Benckler, 2015), concentrando la atención en torno a lo que dicen cuentas líderes o referentes por el número de seguidores. Dicho peligro se constató el mismo día de la huelga general, al observar que un hashtag mal escrito (\#LasPeridiodistasParamos) llegó a ganar en viralidad al establecido por el grupo (gráfico 3).

Con todo, respecto a los canales comunicativos, dos aspectos singularizan este movimiento social. Una diferencia subrayable con movimientos de protesta como el $15 \mathrm{M}$ e incluso con las olas feministas anteriores, es que por primera vez los medios de comunicación de masas tradicionales no pueden ignorarlas y han cubierto sus acciones. Si bien desde el surgimiento de la web el feminismo ha buscado continuamente estrategias discursivas para la obtención de nuevos terrenos de expresión y reivindicación (García-Manso; Silva-e-Silva, 2017), ahora tiene a su lado a la radio y la televisión, medios en los que trabajan periodistas implicadas.

Y otro motivo por el que se ha individualizado a este movimiento es porque ha servido para movilizar con sus peticiones a mujeres de otros sectores profesionales, clases sociales y edades. 
"Creo que contagiamos a muchas personas, especialmente cuando se sumaron las periodistas conocidas de televisión y radio, como Pepa Bueno y Ana Rosa Quintana. Tanto el chat de investigadoras como el de actrices nos pedían ayuda. Se generó una conciencia muy necesaria" (Mercedes Domènech).
Twitter ayuda a visibilizar la movilización, pero no es un escenario de construcción de consenso

Por tanto, la difusión sigue el modelo establecido por la teoría del círculo concéntrico que explican Micó y Casero-Ripollés (2014): comunicación interpersonal -directa o mediante tecnología- entre grupos de amistad o compañerismo; internet; y medios de masas, que consiguen la popularización de mensaje. Es aquí cuando se plantea el interrogante de qué hubiera ocurrido si no se suman periodistas líderes del sector audiovisual.

Tras su consolidación, el movimiento digital \#lasperiodistasparamos ha provocado, en aras de su eficiencia en el espacio público oposicional, la creación de nuevas identidades políticas en la esfera del activismo feminista. Se trata de asociaciones, plataformas y organizaciones profesionales feministas, redes considerablemente más pequeñas -también en el número de participantes activas e implicadas-, pero con capacidad de decidir y actuar en comunidades dentro del espacio urbano.

Todas las organizaciones cuentan con canales propios en Telegram, medio en el que se coordinan para tomar decisiones en asambleas físicas. Y también todas ellas disponen de cuentas en Twitter para visibilizar sus acciones, publicitar agendas feministas y ejercer una autorregulación dinámica; es decir, denunciar públicamente prácticas deontológicamente incorrectas dentro de la propia profesión con el objetivo de poner fin a las representaciones e imaginarios sociales de dominación machista (Giraldo-Luque; Fernández-García; Pérez-Arce, 2018).

Aunque todavía es pronto para evaluar el éxito de este movimiento, al menos sí se le debe reconocer la gestación de un compañerismo que hasta ahora no se había detectado y que, aunque con menos participantes, sigue vivo. También el haber dado el paso de impulsar nuevas rutinas productivas, de organización y de autorregulación para cambiar un sistema desigual en cuanto a género. El activismo enmarcado en \#lasperiodistasparamos puede considerarse un éxito social en tanto ha generado una colectividad en una profesión disgregada, individualista y poco dada a la defensa conjunta de derechos laborales y profesionales.

Con todo, la ausencia de mejoras laborales, cambios productivos que no garantizan la perspectiva de género, debates silenciados por temas conflictivos, el no cuestionamiento del sistema capitalista y el ciberacoso son los principales frentes del movimiento feminista dentro de la profesióne.

La fuerza de este movimiento dependerá de su capacidad para incorporar sus argumentos y resoluciones asamblearias en el ideario de la tecnopolítica contemporánea (Elías, 2018, p. 59). Especialmente la del propio sector de la comunicación, donde el liderazgo, según datos del Informe anual de la Profesión Periodística de la Asociación de la Prensa de Madrid presentado a finales de 2018 (APM, 2018), aún reside en los varones. De los 268 cargos de gestión en los equipos directivos de las 30 mayores empresas de medios de España, el $75 \%$ lo ocupan hombres y el $25 \%$ mujeres. Respecto a los medios públicos españoles (agencias y radiotelevisiones estatal y autonómicas), de los 176 cargos directivos, el 73\% son hombres y un $27 \%$ mujeres. Tan sólo las nuevas plataformas de información digitales constituyen el nicho del mercado laboral donde se observan los avances más firmes hacia la igualdad (De-Miguel-Pascual; Hanitzsch; Parratt; Berganza, 2017; De-Miguel-Pascual; Parratt-Fernández; Berganza, 2019). En este trabajo también debe implicarse a las universidades, responsables de la formación deontológica y en igualdad del estudiantado en las áreas

El movimiento ha servido para movilizar con sus peticiones a mujeres de otros sectores profesionales, clases sociales y edades de Comunicación.

\section{Notas}

a. No obstante, el \#MeToo había sido ideado 11 años antes (2006) por la activista social Tarana Burke para promover el "empoderamiento a través de empatía" entre mujeres negras que habían experimentado abuso sexual particularmente en las comunidades desfavorecidas.

b. En este listado se han eliminado cuentas de robots que informan con cierta frecuencia de los trending topics en España:

- TTEspaña (@ttesbot), con 53 tweets;

- Uno SEO (@UnoSEOcom), con 44 tweets;

- Anuncio público (@AnuncioPublico1),con 44 tweets;

- Fue tendencia (@fuetendencia),con 42 tweets;

- Postre dulce (@PostreDulce), con 43 tweets;

- Siguai\&Sicaco (@siguaiysicaco), con 43 tweets. 
c. Se debe explicar que el segundo de los registros no debe valorarse, ya que se refiere al recurso utilizado textualmente para incluir a los géneros masculino y femenino en un plural.

d. Alicia G. Montano falleció en enero de 2020. Desde entonces el cargo de Editora de Igualdad de TVE lo ejerce Carolina Pecharromán (nota añadida en el proceso de maquetación).

e. En el marco de la primera asamblea en Madrid, celebrada el 2 de junio de 2018, la Plataforma en Defensa de Libertad de Información (PDLI) lanzó el Observatorio contra el Acoso Online a Mujeres Periodistas para visibilizar este problema y llamar la atención sobre su magnitud.

http://libertadinformacion.cc

\section{Referencias}

APM (2018). Informe anual de la profesión periodística 2018. Madrid: Asociación de la Prensa de Madrid. https://www.apmadrid.es/wp-content/uploads/2019/03/La-mujer-en-el-periodismo-Informe-2018.pdf

Arroyas-Langa, Enrique; Martínez-Martínez, Helena; Berná-Sicilia, Celia (2018). "Twitter como espacio alternativo a la esfera política institucional. Análisis retórico de las estrategias discursivas de Podemos durante la moción de censura contra Rajoy". En: Tur-Viñes, Victoria (dir.); Segarra-Saavedra, Jesús; Hidalgo-Marí, Tatiana; Rodríguez-Ferrándiz, Raúl (coords.). Actas de las Jornadas científicas internacionales sobre análisis del discurso en un entorno transmedia. Alicante: Universidad de Alicante, pp. 85-94. ISBN: 9788461793860

https://doi.org/10.14198/MEDCOM/2017/11_cmd

Baer, Hester (2016). “Redoing feminism: Digital activism, body politics, and neoliberalism”. Feminist media studies, v. 16, n. 1, pp. 17-34.

https://doi.org/10.1080/14680777.2015.1093070

Bakardjieva, Maria (2009). "Subactivism: Lifeworld and politics in the age of the internet". The information society, v. 25, n. 2, pp. 91-104.

https://doi.org/10.1080/01972240802701627

Barker, Chris; Jane, Emma A. (2016). Cutural studies. Theory and practice. Thousand Oaks, CA: Sage. ISBN: 9781 473919457

Benckler, Yochai (2015). La riqueza de las redes: Cómo la producción social transforma los mercados y la libertad. Barcelona: Icaria. ISBN: 9788498886344

Bernal-Triviño, Ana (2019). No manipuléis el feminismo. Barcelona: Espasa. ISBN: 9788467057034

Borderías-Mondéjar, Cristina; Carrasco-Bengoa, Cristina; Alemany, Carme (comp.) (1994). Las mujeres y el trabajo: rupturas conceptuales. Barcelona/Madrid: Icaria/Fuhem. ISBN: 8474262372

Caro-Castaño, Lucía (2015). “Construir y comunicar un 'nosotras' feminista desde los medios sociales. Una reflexión acerca del 'feminismo del hashtag'". Commons: Revista de comunicación y ciudadanía digital, v. 4, n. 2, pp. 124-154. https://revistas.uca.es/index.php/cayp/article/view/3098

Castells, Manuel (2015). Redes de indignación y esperanza. Los movimientos sociales en la era de internet. Madrid: Alianza Editorial. ISBN: 9788420609607

Chaher, Sandra; Santoro, Sonia (comp.) (2007). Las palabras tienen sexo. Introducción a un periodismo con perspectiva de género. Buenos Aires: Artemisa Comunicación Ediciones. ISBN: 9789872361105

Chocarro, Silvia (coord.) (2007). Nosotras en el país de las comunicaciones. Miradas de mujeres. Barcelona: Icaria Editorial. ISBN: 9788474267365

Cimac (2009). Hacia la construcción de un periodismo no sexista. México DF: Comunicación e Información de la Mujer. https://cutt.ly/ywXi9k8

Cobo, Rosa (2019). "La cuarta ola feminista y la violencia sexual”. Paradigma, revista universitaria de cultura, v. 22, pp. 134-138. https://dialnet.unirioja.es/servlet/articulo?codigo $=6983521$

De-Miguel, Ana; Boix, Montserrat (2002). “Los géneros de la Red: los ciberfeminismos”. Mujeres en Red. Periódico feminista.

http://www.mujeresenred.net/IMG/pdf/ciberfeminismo-demiguel-boix.pdf

De-Miguel-Pascual, Roberto; Hanitzsch, Thomas; Parratt, Sonia; Berganza, Rosa (2017). “Women journalists in Spain: An analysis of the sociodemographic features of the gender gap". El profesional de la información, v. 26, n. 3, pp. 497-506.

https://doi.org/10.3145/epi.2017.may.16

De-Miguel-Pascual, Roberto; Parratt-Fernández, Sonia; Berganza, Rosa (2019). “Las percepciones de las mujeres periodistas sobre su trabajo. La variable género en la cultura profesional”. Revista latina de comunicación social, pp. 1818-1833. http://www.revistalatinacs.org/074paper/1412/95es.html 
Dema-Moreno, Sandra; Díaz-Martínez, Capitolina (2010). "Gender inequalities and the role of money in Spanish dual-income couples". European societies, v. 12, n. 1, pp. 65-84.

https://doi.org/10.1080/14616690903219181

Diani, Mario (2000). "Social movement networks virtual and real". Information, communication \& society, v. 3, n. 3, pp. 386-401.

https://doi.org/10.1080/13691180051033333

Ekman, Joakim; Amna, Erik (2012). "Political participation and civic engagement: Towards a new trilogy". Human affairs, v. 22, n. 3, pp. 283-300.

https://doi.org/10.2478/s13374-012-0024-1

Elías, Carlos (2018). “Activismo y comunicación en la era digital: ¿Perjudican las redes sociales la movilización ciudadana?". Icono 14, v. 16, n. 1, pp. 42-63.

https://doi.org/10.7195/ri14.v16i1.1126

Fagoaga, Concha; Secanella, Petra-María (1984). Umbral de presencia de las mujeres en la prensa española. Madrid: Instituto de la Mujer. ISBN: 8450507383

Fotopoulou, Aristea (2014). "Digital and networked by default? Women's organisations and the social imaginary of networked feminism". New media \& society, v. 18, n. 6, pp. 989-1005.

https://doi.org/10.1177/1461444814552264

Gallagher, Margaret (1979). El modo de presentar a la mujer en los medios de comunicación. París: Unesco.

Gallego, Juana (1994). El sostre de vidre. Situació sòcio-professional de les dones periodistes. Barcelona: Institut Català de la Dona. ISBN: 9788439327318

Gallego, Juana (coord.) (2002). La prensa por dentro: producción informativa y transmisión de estereotipos de género. Barcelona: Los libros de la frontera. ISBN: 8482550608

García-de-Cortázar, Marisa; García-de-León, María-Antonia (coord.) (2000). Profesionales del periodismo: hombres y mujeres en los medios de comunicación. Madrid: CIS. ISBN: $847476310 \mathrm{X}$

García-Manso, Almudena; Silva-e-Silva, Artenira (2017). “Ciberfeminismo o feminismo en la red: Haciendo arqueología en internet". Antropología experimental, v. 17, pp. 277-286.

https://doi.org/10.17561/rae.v0i17.3515

Gil de Zúñiga, Homero; Huber, Brigitte; Strauß, Nadine (2018). "Social media and democracy". El profesional de la información, v. 27, n. 6, pp. 1172-1180.

https://doi.org/10.3145/epi.2018.nov.01

Giraldo-Luque, Santiago; Fernández-García, Núria; Pérez-Arce, José-Cristian (2018). "La centralidad temática de la movilización \#NiUnaMenos en Twitter". El profesional de la información, v. 27, n. 1, pp. 96-105.

https://doi.org/10.3145/epi.2018.ene.09

Gutiérrez-Rubí, Antonio (dir.) (2019). La comunicación del movimiento feminista en el Estado español. Ideograma; Fondo Calala de Mujeres; Open Initiative for Europe; Open Society Foundations.

https://www.ideograma.org/wp-content/uploads/2019/03/COMUNICACION_MOVIMIENTO_FEMINISTA_IDG.pdf

Jimsook, Kim (2017). “\#iamafeminist as the 'mother tag': Feminist identification and activism against misogyny on Twitter in South Korea". Feminist media studies, v. 17, n. 5, pp. 804-820.

https://doi.org/10.1080/14680777.2017.1283343

Knappe, Henrike; Lang, Sabine (2014). "Between whisper and voice: Online women's movement outreach in the UK and Germany". European journal of women's studies, v. 21, n. 4, pp. 361-381.

https://doi.org/10.1177/1350506814541643

Lagarde, Marcela (1996). Género y feminismo: desarrollo humano y democracia. Madrid: Horas y Horas. ISBN: 97884 87715600

Larrondo-Ureta, Ainara (2005). "La Red al servicio de las mujeres. Aproximación a la relación mujer y medios de comunicación en internet". Estudios sobre el mensaje periodístico, v. 11, pp. 375-392.

https://revistas.ucm.es/index.php/ESMP/article/view/ESMP0505110375A

Leavy, Patricia L. (2007). “The feminist practice of content analysis". In: Hesse-Beber, Sharlene N.; Leavy, Patricia L. (eds.) Feminist research practice: A primer. Thousand Oaks: Sage. ISBN: 9780761928928

López, Kimberly J.; Muldoon, Meghan; McKeown, Janet K. L. (2019). “One day of \#Feminism: Twitter as a complex digital arena for wielding, shielding and trolling talk on feminism". Leisure sciences, v. 41, n. 3, pp. 203-220.

https://doi.org/10.1080/01490400.2018.1448022 
López-Meri, Amparo (2015). “El impacto de Twitter en el periodismo: un estado de la cuestión”. Revista de la Asociación Española de Investigación de la Comunicación, v. 2, n. 4, pp. 34-41.

http://www.revistaeic.eu/index.php/raeic/article/view/55

Mattelart, Michèle (1982). Mujeres e industrias culturales. Barcelona: Anagrama. ISBN: 8433907646

McRobbie, Angela (2009). The aftermath of feminism: Gender, culture and social change. London: Sage. ISBN: 9780 761970620

Mendes, Kaitlynn; Ringrose, Jessica; Keller, Jessalynn (2018). “\#Metoo and the promise and pitfalls of challenging rape culture through digital feminist activism". European journal of women studies, v. 25, n. 2, pp. 236-246.

https://doi.org/10.1177/1350506818765318

Micó, Josep-Lluís; Casero-Ripollés, Andreu (2014). "Political activism online: Organization and media relations in the case of 15M in Spain". Information, communication \& society, v. 17, n. 7, pp. 858-871.

https://doi.org/10.1080/1369118X.2013.830634

Negt, Oskar (2007). L'espace public oppositionnel. Paris: Editions Payot. ISBN: 9782228902021

Núñez-Puente, Sonia; Vázquez-Cupeiro, Susana; Fernández-Romero, Diana (2016). “Ciberfeminismo contra la violencia de género: análisis del activismo online-offline y de la representación discursiva de la víctima". Estudios sobre el mensaje periodístico, v. 22, n. 2, pp. 861-877.

https://doi.org/10.5209/ESMP.54240

Ortega, Félix; Humanes, María-Luisa (2000). Algo más que periodistas. Sociología de una profesión. Barcelona: Ariel. ISBN: 8434418142

Plant, Sadie (1997). Zeros + ones: Digital women and the new technoculture. London: Fourth Estate. ISBN: 9781 857026986

Reverter-Bañón, Sonia (2001). “Reflexiones en torno al ciberfeminismo”. Asparkía. Investigació Feminista, n. 12, pp. 35-51. https://www.e-revistes.uji.es/index.php/asparkia/article/view/883

Reverter-Bañón, Sonia (2013). "Ciberfeminismo: de virtual a político”. Teknokultura. Revista de cultura digital y movimientos sociales, v. 10, n. 2, pp. 451-461.

http://repositori.uji.es/xmlui/handle/10234/84352

Rodríguez-Ruibal, Antonio; García-López, Javier (2013). “Uso y funciones de Twitter en periodistas españoles”. Estudios sobre el mensaje periodístico, v. 19, pp. 963-969.

https://doi.org/10.5209/rev_ESMP.2013.v19.42181

Rovetto-Gonem, Florencia (2013). "Percepciones sobre desigualdades de género en el trabajo periodístico". Global Media Journal, v. 10, n. 20, pp. 54-73.

https://www.redalyc.org/articulo.oa?id=68730969004

Sánchez-Duarte, José-Manuel; Fernández-Romero, Diana (2017). "Subactivismo feminista y repertorios de acción colectiva digitales: prácticas ciberfeministas en Twitter". El profesional de la información, v. 26, n. 5, pp. 894-902.

https://doi.org/10.3145/epi.2017.sep.11

Sassen, Saskia (2003). "Mediating practices: Women with/in cyberspace”. In: Armitage, John; Roberts, Joanne (eds.). Living with cyberspace. Technology and society in the 21 st century. New York: Continuum. ISBN: 9780826460363

Sierra-Caballero, Francisco (2018). “Ciberactivismo y movimientos sociales. El espejo público oposicional en la tecnopolítica contemporánea". Revista latina de comunicación social, v. 73, pp. 980-990.

https://doi.org/10.4185/RLCS-2018-1292

Springer, Claudia (1996). Electronic eros: Bodies and desire in the postindustrial age. Austin: University of Texas Press. ISBN: 9780292776975

Turley, Emma; Fisher, Jenny (2018). "Tweeting back while shouting back: Social media and feminism activism". Feminism \& psychology, v. 28, n. 1, pp. 128-132.

https://doi.org/10.1177/0959353517715875

Van-Aelst, Peter; Walgrave, Stefaan (2002). "New media, new movements? The role of the internet in shaping the 'anti-globalization' movement". Information, communication \& society, v. 5, n. 4, pp. 465-493. https://doi.org/10.1080/13691180208538801

Wolf, Mauro (1987). La investigación en la comunicación de masas. Barcelona: Paidos Ibérica. ISBN: 8475094376 https://catedracoi2.files.wordpress.com/2014/05/wolf-mauro-investigacion-de-la-comunicacion-de-masas.pdf

Woltersdorff, Volker (2011). "Paradoxes of precarious sexualities". Cultural studies, v. 25, n. 2, pp. 164-182. https://doi.org/10.1080/09502386.2011.535984 